\title{
Research on the Enlightenment of Knowledge Management to Archive Work
}

\author{
Yan Fang ${ }^{1}$ \\ ${ }^{1}$ Qilu Normal University, Jinan City, Shandong Province, 250013
}

Keywords: enlightenment; knowledge management; archive work

\begin{abstract}
As a brand-new management idea and management method, knowledge management has become more and more important with the development of society, and it has great enlightenment for archives management. This paper describes the meaning of knowledge management, the reasons for the rise and the new characteristics of knowledge management, and in-depth analysis of the status quo of the file management work, puts forward the problems that exist, and discusses the knowledge management of the information age for file management.
\end{abstract}

\section{Introduction}

With the development of information technology and network technology, traditional file management methods and management concepts have increasingly exposed their deficiencies. The utilization of file resources is low, and the file staff has poor enthusiasm for work. The archival department has become the internal consumption department with low output. trend. In a company with a strong cost-effectiveness concept, if the archives management cannot be improved, if the archives department cannot create value for the enterprise, it will eventually be marginalized. With the advent of the era of knowledge economy, knowledge management has been enthusiastically discussed by people from all walks of life. Introducing it into the practice of archives will also bring new opportunities for the development of archives management [1]. This article will initially discuss the relationship between enterprise file management and knowledge management and knowledge management's implications for archive work.

\section{The Definition of Knowledge Management}

The definition of Larry Prusak, Dean of the IBM Knowledge Management Institute, "a fluid mixture of established empirical, value, coherent information, and expert insights that can provide a framework for measuring and absorbing new experiences and information. It is produced in and used by the intellectuals. In the organization, knowledge exists not only in documents or archives but also in daily management, processes, behaviors and norms." The definition of "Father of Knowledge Management" Davenporter, based on fully affirming the value of knowledge to the enterprise, creates an environment for each employee to acquire, share, and use internal and external organizations through specific information technologies. Knowledge information forms personal knowledge, and supports and encourages individuals to apply and integrate knowledge into organizational products and services. Ultimately, it improves enterprise innovation ability and management theory and practice of speed of market response [2].

Microsoft's definition, organization, fluency and technology synthesis, provide information for knowledge workers. Knowledge assets exist in the organization, so identifying intellectual assets is the primary task of knowledge management; the other half is to overcome the cultural barriers in the organization. Any knowledge management must be combined with the business process flow, so check the strengths and weaknesses of the company's processing flow and look for links that may bring profitability. Technology is a means to implement a knowledge management system, including technological innovation and technology applications. 


\section{Re-analysis of the Current Status of File Management}

School archives are an important source of knowledge for the school. File management is an important part of school knowledge management. The school's knowledge resources refer to the knowledge and management system accumulated by the school in subject construction, education and teaching, and scientific research activities. It includes knowledge itself and the management concepts, ideas and cultures formed in the management, management modes and methods, and so on. Since the archive is an important knowledge resource for the school, file management itself is a kind of management activity and process for knowledge. It involves the school's supervision, assistance, and control of file formation, accumulation, organization, and archiving, as well as the collection, sorting, cataloging, identification, storage, statistics, retrieval, development, and utilization of archives. At present, most colleges and universities have comprehensive filing rooms, but they are lack of standardization and systematicness. Compared with the social development and the requirements of the times, there are still large gaps and deficiencies in file management. The major manifestations are:

The concrete manifestation of the lack of awareness of archives is that people do not know enough about the importance of archives and do not know enough. In people's minds, archival work is nothing more than simply collecting, sorting, and keeping something that has become history. It is simple labor and does not have much meaning. Some leaders think that the quality of archives work is irrelevant and that performance evaluation is not linked to archives work. There is no need to work hard on archives [3].

The situation of information appreciation directly determines the cost and quality of new knowledge production. For knowledge-intensive organizations, information is the raw material, and professionals who process and analyze these information are knowledge creators. However, archivists generally have the following problems: First, the quality of archivists is not high enough and the business is not proficient. Many file management personnel are "multiple employees" who have left home halfway, do not pay attention to professional ethics education and job training, and have not worked through business study and training; some units do not pay attention to computers and love the archival career in terms of file staffing. The silently dedicated personnel serve as full-time archivists. They do not pay attention to academic qualifications, business, and quality. Even if they have high academic qualifications, they are not professional in archival studies and it is difficult to meet the needs of the development of the times and archival work. Second, the file sector is poorly treated and the team is unstable. Compared with other related departments, archivists have poor salaries, low wages, and large bonus welfare gaps. The archives department received unfair treatment in terms of promotion, promotion, and job title evaluation. Compared with the relevant book series, the archives department received a great deal of difference. As a result, the archives work was not taken seriously by the leaders in the organization and many of the cadres in the archives department were assigned. People don't want to come. Even if they come, they don't feel at ease. Some of them are trying to mobilize. Some are stupid, keep the balance, and the staff in the archives department is ideologically unstable. They don't study hard and delve deep into business knowledge.

To carry out the archives work smoothly and effectively requires an essential material basis. However, some units did not even include the archives work funds in their plans, and some even if they were included in the plan, the proportion of which was very small, resulting in incomplete file equipment, poor hardware facilities, specifically: no fixed files Treasury, randomly find a house as a warehouse, find a few cabinets to store files, easy to cause the phenomenon of file wear, damage, loss; management is not standardized, some of the unit files on the office, file cabinets randomly placed in the wall; hardware equipment Incomplete, such as dehumidifiers, magnetically shielded cabinets, air conditioners, and other necessary equipment are not available, failing to meet the most basic conditions for protecting files and extending their life span; most of the technical equipment are obsolete, such as classified volumes, indexing directories, and retrieval work. Is a traditional manual operation, computer management in many file management departments have not kept up 
with the actual needs, especially the hardware construction of rural primary and secondary school file management. Hardware construction is the basis for raising the file level of rural primary and secondary schools, and it is also an important guarantee for the quality of file management. However, many rural primary and secondary schools do not include the construction of file facilities in the overall planning of school infrastructure [4]. Due to poor financial conditions in rural primary and secondary schools, there are not enough archives warehouses, and there are no basic equipment such as air conditioners, dehumidifiers, and pest control, fire prevention, and anti-theft devices in the warehouses; especially for archives with special storage requirements such as audiovisual, physical, and electronic documents, etc., did not set up special warehouses, which seriously affected the preservation period of archives. Therefore, the existing file management work can not meet the needs of the development of the times. File management should develop with the development of the times, update with the update of technology, absorb the concept of knowledge management, learn from knowledge management methods, and work on file management. It will be of great benefit.

\section{The Inspiration of Knowledge Management on the Archives Work}

Absorption of knowledge management concepts, attention to tacit knowledge mining Knowledge management theory of tacit knowledge and the study of explicit knowledge of tacit knowledge suggest that the archives work should not only focus on the explicit knowledge generated within the organization (documents The collection and management of, and importance of, the discovery of tacit knowledge hidden within the organization. This part of the knowledge plays a decisive role in the development and continuation of the organization. Although tacit knowledge is highly personalized and perceptual, however, the development of information technology has provided good technical conditions for the manifestation of tacit knowledge. Archivists need to actively analyze tacit knowledge hidden in the organizational management process, organizational culture, and organizational members' minds. In recognition, the archives department must establish and maintain a close and friendly relationship with individuals and organizations that have tacit knowledge, and establish a channel for expanding knowledge collection through the platform of the Internet. The work experience and technology of each department and each member will be established. Materials, post-retirement writings, opinions expressed during participation in various seminars and seminars, etc. These materials contain their personal sentiments, work experience, evaluation of working units, hopes, and very valuable knowledge. It can provide latecomers with enlightenment and encouragement and provide various help for the development of the unit. If archival work can not only provide the original archival information required by the organization, but also the knowledge hidden in the organization can be excavated, processed, integrated, and provided in the form of knowledge products, so that the people who use it can feel the knowledge. Valuable, then the value of archival work can be more fully revealed.

Archives are an important source of knowledge. This is undoubtedly the only way to maximize the value of knowledge resources is to share them. However, the continual nature of archives has led to the conservative concept that archival work is easy to use. Occupying a dominant position, this conservative concept often blocks the effective communication between the archival department and users, and makes archival, an important knowledge resource, fail to play its due role. This is in line with the current development and sharing of information resources. The strong contrast created by the request caused great dissatisfaction among the users and impeded the realization of the value of the archives work. In the long run, the archival work must have lost its important position in the social life because it had left its service provider. The archives department should be inspired by the highly shared ideal of knowledge depicted by knowledge management. Files can only show value when they are used. Archival work can only transmit archive information to the most needy people in a timely manner in the right form. It shows the significance of the work and the purpose of the work. What the current archiving department needs to do is to change the way of thinking and management centering on archival entities. Instead, it takes user-centered thinking and management methods as the goal, and takes the sharing of archival information 
resources as the goal, and vigorously conducts archival information resources. The development and implementation of a variety of forms of file utilization services will give full play to the advantages of the archives department. At present, many organizations have already established an information center based on the archives department. The archives department should make full use of a variety of knowledge resources, break through the barriers of artificial use, and provide users with multifaceted, multi-perspective, multi-channel knowledge services. Promote the sharing of knowledge [5].

The era of knowledge economy requires more talents with knowledge and skills than ever before. However, the rapid development of science and technology and the rapid renewal of knowledge have made lifelong learning and continuing education an indispensable part of people's lives. For any kind of organization, to establish a firm foothold in the competition, it is necessary to continuously improve the technological level, improve management methods, and accumulate organizational knowledge. Whether it is an organization or an individual, only by continuous learning can we have the ability to survive and the vitality of development. For the archival department, it is facing difficulties in the theory and technology of archival management brought about by information technology. It is also necessary to build a learning organization and create a good organizational environment for the development of individuals and organizations. The archives department must cultivate and create a cultural atmosphere of knowledge sharing and mutual benefit, strive to create a good communication situation, pay attention to personnel training and continuing education, and provide good conditions for their members to learn from the organization and increase their ability. At the same time, members of their own departments are also encouraged to think positively, conscientiously study modern management techniques, be bold in innovation, and contribute their own experience and technology to the development of the archives industry.

The high cost is often considered by researchers to be a basic feature of knowledge management. Because knowledge management activities for the effective management of knowledge assets need to invest money or labor, apparently these researchers neglected that they neglected the use of Some knowledge management departments and foundations, if they can effectively use existing departments and personnel, can greatly reduce the cost and risk of knowledge management. Knowledge management is similar to archival work in terms of its purpose, management activities, and its specific technologies. Almost every archival department in each organization is the backbone of knowledge management that should not be forgotten. It can confidently say that An organization that implements knowledge management and does not support participation in archival work is unimaginable and impossible to achieve. Because from the perspective of knowledge management, archival is a basic knowledge source that an organization must possess, and it is organizational explicit knowledge. The important part of the project is; From the perspective of knowledge management activities, the establishment of a knowledge management system will inevitably involve the collection, identification, classification, integration, retrieval, and transmission of knowledge, and the archives and archivists have long been accumulating in long-term practice of archival work. This knowledge, they are familiar with the sources of information, are good at identifying knowledge, longer than the retrieval and distribution of knowledge; from the point of view of specific knowledge management technology, document management technology is the key technology to deal with explicit knowledge, which is also a file Work with familiar technology. In addition, archivists also have the patience and attentive qualities necessary for knowledge managers to facilitate the discovery of tacit knowledge in organizations. Archivists should be fully aware of their own professional strengths, and actively participate in the practice of knowledge management with the courage of others. They should demonstrate their skills in knowledge management and make greater contributions to the development of society [6].

\section{Conclusion}

In summary, in the face of the enthusiasm of knowledge management, archivists must not turn a blind eye. They must clearly realize that if they stick to one's behavior, they will be out of touch 
with society, and ultimately lose their professional advantages and work positions. Only actively and actively Absorption of new management concepts, improvement of working methods, and the transformation of custodians of knowledge into providers of knowledge can enhance the value of their work and expand the impact of archival work.

\section{References}

[1] http://www.blogchina.com/20090806779913.html.

[2] http://www.bokee.net/dailymodule/blog_view.do?id=80500

[3] Hu Liqing, Xu Shenyuan. Research on the Present Situation and Reform of Archives Management [J]. Forum on Library \& Information Science, 2006(4).15

[4] Du Ming, Li Xiangdong. Personal Knowledge Management and Application [J]. Market Modernization, 2005(4).88

[5] Yu Yuanyuan. The Enlightenment of Knowledge Management to Archives Work [J].Archives Science Research, 2007(2).96

[6] Yu Yuanyuan. Enlightenment of Knowledge Management to Archives Work [J].Archives Science Research, 2007(2).103 